\title{
Comparing the Fracture Resistance and Modes of Failure in Different Types of CAD/CAM Zirconia Abutments with Internal Hexagonal Implants: An in Vitro Study
}

\author{
Yu-Tsen Chang \\ Kaohsiung Chang Gung Memorial Hospital \\ Yu-Ling Wu \\ Kaohsiung Chang Gung Memorial Hospital \\ Hung-Shyong Chen \\ Cheng Shiu University \\ Ming-Hsu Tsai \\ Cheng Shiu University \\ Chia-Chen Chang \\ Kaohsiung Chang Gung Memorial Hospital \\ Aaron Yu-Jen Wu ( $\nabla$ dentwu@hotmail.com ) \\ Kaohsiung Chang Gung Memorial Hospital
}

\section{Research Article}

Keywords: zirconia abutments, One-way analysis of variance (ANOVA), statistical evaluation, buccal aspect.

Posted Date: July 28th, 2021

DOI: https://doi.org/10.21203/rs.3.rs-750895/v1

License: (c) (i) This work is licensed under a Creative Commons Attribution 4.0 International License. Read Full License

Version of Record: A version of this preprint was published at Materials on April 4th, 2022. See the published version at https://doi.org/10.3390/ma15072656. 


\section{Abstract}

3 groups of zirconia abutments $(n=3)$ made of different connection design or manufacturers were investigated (All-Zr, ASC-Zr and AM-Zr groups). All-electric dynamic test instrument was used to place static loading on specimen with a crosshead speed set at $1 \mathrm{~mm} / \mathrm{min}$. One-way analysis of variance (ANOVA) and post hoc Tukey tests $(\mathrm{a}=.05)$ were used for statistical evaluation. The mean fracture resistance was $258.21 \pm 68.60 \mathrm{~N}$ for All-Zr group, $360.55 \pm 29.66 \mathrm{~N}$ for ASC-Zr group, and $341.45 \pm 25.97 \mathrm{~N}$ for AM-Zr group. There was no significant difference in fracture resistance between the 3 groups (1-way ANOVA, $P=0.10$ ). The modes of failure among the 3 types of abutments are different. The All-Zr group showed an oblique fracture line starting from the buccal aspect at the region of the implant platform. While in the ASC-Zr group and the AM-Zr group showed a relatively horizontal fracture line with greater distance from implant platform. The titanium inserts cannot significantly improve the fracture resistance of the zirconia abutment. However, they may alter the modes of failure, allowing buccal fracture surfaces of the zirconia abutments to be placed away from the implant platform, thereby protecting the implantabutment connection.

\section{Introduction}

Since their invention, dental implants have been widely applied in dental restorations to restore occlusal function of patients. Titanium implant abutment has exhibited satisfactory biocompatibility and mechanical properties, making it suitable for long-term use in implant-supported prosthesis. However, despite the stable and predictable characteristics of titanium abutments, long-term observations from clinical studies have revealed that an unnatural bluish color may, in certain situations, appear in the gingiva surrounding the titanium abutments, particularly when the implant was inserted too labially and when the gingival biotype of the patient is thinner ${ }^{1-5}$.

With the development of ceramic materials, computer-aided design and computer-aided manufacturing (CAD/CAM) technology, and patient demands for aesthetically pleasing prosthesis, ceramic materials are gradually applied to implant abutments ${ }^{6,7}$. The first all-ceramic abutment was manufactured using densely sintered alumina $\left(\mathrm{Al}_{2} \mathrm{O}_{3}\right)$. However, studies have reported that $\mathrm{Al}_{2} \mathrm{O}_{3}$ has low fracture resistance ${ }^{8,9}$. Zirconia was used as abutment material in 1996 , which is more resistant to fracture than alumina ${ }^{10}$. Zirconia allows a certain degree of light transmission, enables dental technologists to create prostheses that satisfy the aesthetic needs of patients ${ }^{11}$.

Zirconia abutments can be manufactured in the form of one-piece or two-piece abutments. One-piece abutments are entirely made of zirconia in their abutment body and implant-abutment connections. In vitro studies have reported that these abutments are sufficiently resistant to the maximal incisal force in the anterior region $(90-370 \mathrm{~N}){ }^{12-16}$. Mitsias et al. ${ }^{17}$ reported that the mean fracture resistance of onepiece zirconia abutments with internal connection is $690 \pm 430 \mathrm{~N}$. Kim et al. ${ }^{18}$ tested one-piece CAD/CAM zirconia abutments with internal connection using static loading and reported mean fracture load of 
$480.01 \pm 174.46$ N. However, numerous clinical reports have recorded cases in which one-piece zirconia abutments fractured ${ }^{19}$. Leutert et al. ${ }^{20}$ compared titanium and one-piece zirconia abutments with respect to their fracture resistance under static load. The one-piece zirconia abutments showed a low fracture strength when attached to tissue-level Straumann implants (158 $\pm 34.7 \mathrm{~N})$, thus being inapplicable in clinical use regardless of the position of the implant. These findings led to the invention of two-piece abutments, which comprise titanium inserts and zirconia abutment body, and can be attached to each other through friction-fit or bonding manner. These abutments are reported to be both aesthetically pleasing and strongly resistant to fracture ${ }^{21}$.

In clinical reality, dentists, patients, and dental technologists may opt for non-original abutments in light of their lower cost and convenience ${ }^{22}$. Some aftermarket manufacturers have begun producing CAD/CAM zirconia abutments, a number of non-original prosthetic kits are also available in the market. However, standards and regulations have not been formulated for the design and quality of manufactured abutments. Limited studies have compared the mechanical properties of two-piece original equipment manufacturing (OEM) and aftermarket zirconia abutments. The effects of the design changes of implant-abutment connection on mechanical properties and intraoral performance of entire implant system is unclear ${ }^{23}$. Further research is needed to verify whether the zirconia abutment made of aftermarket manufacturer has the mechanical properties required for clinical use.

The purpose of this in vitro study is to compare the fracture resistance and modes of failure under static loading in 3 different types of zirconia abutments attached to implants with standard diameters and internal hexagonal connection. The proposed null hypothesis states that these zirconia abutments do not differ in fracture resistance and modes of failure under static loading.

\section{Methods}

Nine zirconia implant abutments with following three designs $(n=3)$ were used (Table 1): the abutments of group All-Zr are one-piece implant abutments, which are entirely composed of zirconia (NobelProcera CAD/CAM Zirconia Abutment, Nobel Biocare, Yorba Linda, Calif). The abutments of ASC-Zr and AM-Zr groups are two-piece implant abutments (Fig. 1). The ASC-Zr abutment contains a titanium insert with an axial wall height of $1 \mathrm{~mm}$, which is friction-fitted with the zirconia component (NobelProcera ASC Abutment; Nobel Biocare, Yorba Linda, Calif). The AM-Zr abutment contains a $2 \mathrm{~mm}$ high titanium insert made by an aftermarket manufacturer, which is bonded to the zirconia component (VITA In-Ceram ${ }^{\circledR}$ YZ DISC Color light, Germany). 
Table 1

Zirconia abutments evaluated

\begin{tabular}{|llll|}
\hline Material & $\begin{array}{l}\text { Abutment } \\
\text { composition }\end{array}$ & $\begin{array}{l}\text { Abutment/Implant } \\
\text { Platform Interface }\end{array}$ & Manufacturer \\
\hline $\begin{array}{l}\text { OEM NobelProcera CAD / CAM } \\
\text { Zirconia Abutment }\end{array}$ & Zirconia & Zirconia / Titanium & $\begin{array}{l}\text { Nobel } \\
\text { Biocare, } \\
\end{array}$ \\
\hline $\begin{array}{l}\text { OEM NobelProcera CAD / CAM } \\
\text { ASC Abutment }\end{array}$ & Zirconia + Ti insert & Titanium / Titanium & $\begin{array}{l}\text { Yorba Linda, } \\
\text { Calif }\end{array}$ \\
& (friction fit) & & $\begin{array}{l}\text { Nobel } \\
\text { Biocare, }\end{array}$ \\
\hline Aftermarket CAD / CAM & & & $\begin{array}{l}\text { Yorba Linda, } \\
\text { Calif }\end{array}$ \\
zirconia abutment on Ti insert & Zirconia + Ti insert & Titanium / Titanium & JingGang, \\
& & & Tainan, \\
\hline
\end{tabular}

A prefabricated titanium abutment (NobelReplace Abutment Conical Connection RP 3 mm) (Fig. 2) was designated as the prototype abutment and scanned with a scanner (NobelProcera 2G scanner, NobelBiocare, Kloten, Switzerland). The abutments of All-Zr and ASC-Zr groups were then obtained from OEM manufacturer Nobel Biocare and abutments from AM-Zr group were milled by the milling machines (Arum 5X-150; DoowonID Co, Daejeon, Korea). In this way, all the abutments are manufactured such that their external dimensions were identical, with a $0.5 \mathrm{~mm}$ deep circumferential chamfer and $9.5 \mathrm{~mm}$ of incisogingival height (Fig. 3).

The zirconia abutments of group AM-Zr requires the bonding of titanium inserts. The surface of the titanium inserts and the intaglio surface of the zirconia abutments were sandblasted and an alloy primer (M.L. Primer; Shofu, Kyoto, Japan) was applied over titanium insert. The titanium inserts and the zirconia abutments were bonded with dual-polymerized composite resin adhesive (RelyX U200 Self-adhesive Resin Cement; 3M ESPE) bonding. Excess adhesive was removed at x10 magnification.

Nine implant fixtures (NobelReplace Conical Connection PMC RP $4.3 \times 10 \mathrm{~mm}$, Yorba Linda, Calif) with internal hexagonal connection and regular platform were used. By scanning each abutment with scanner (NobelProcera 2 G scanner, NobelBiocare, Kloten, Switzerland), zirconia crowns (VITA In-Ceram ${ }^{\circledR}$ YZ DISC Color medium, Germany) with an $11 \mathrm{~mm}$ incisogingival height and $8.5 \mathrm{~mm}$ mesiodistal width were made for each abutment. The implant abutment and the intaglio surface of the zirconia crown were sandblasted and treated with a ceramic primer (Cera-Resin Bond, CRB, Shofu Dental, Kyoto, Japan). A dual-cure resin cement (RelyX U200 Self-adhesive Resin Cement; 3M ESPE) was used to bond the crown to the abutment. After removing the excess adhesive, a preload of $35 \mathrm{Ncm}$ was applied according to the manufacturer's instructions to tighten all the abutments to implant fixtures. 
The specimen was fixed on a metal jig, with a tilting in $30^{\circ}$ angulation of the long axis of implant fixture to simulate the Class I incisor relationship ${ }^{24-28}$. All-electric dynamic test instrument (ElectroPulsTM E3000, Instron, USA) was used to measure the fracture strength of the zirconia abutments (Fig. 4). A metal rod was used to place loading at $2 \mathrm{~mm}$ lingual from the incisal edge of zirconia crown. The speed of the testing machine was set at $1 \mathrm{~mm} / \mathrm{min}$. The crosshead motion stopped after the load started to decrease due to fracture of the zirconia component or the plastic deformation of the screw or implant fixture. The value was recorded as failure load and one-way analysis of variance (ANOVA) and post hoc Tukey tests $(a=.05)$ were used for statistical evaluation. In addition, the mode of failure of abutments was studied and analyzed under a digital microscope (VHX-950F, Keyence, Belgium).

\section{Results}

The mean fracture resistance was $258.21 \pm 68.60 \mathrm{~N}$ for All-Zr group, $360.55 \pm 29.66 \mathrm{~N}$ for ASC-Zr group, and $341.45 \pm 25.97 \mathrm{~N}$ for $\mathrm{AM}-\mathrm{Zr}$ group (Table 2). There was no significant difference in fracture resistance between the 3 groups (1-way ANOVA, $P=0.10$ ).

Table 2

Mean fracture resistance of zirconia abutments

\begin{tabular}{|lccc|}
\hline Mean fracture resistance $(\mathrm{N})$ & $\mathbf{n}$ & mean & SD \\
\hline Group & 3 & 258.21 & 68.60 \\
\hline NobelProcera CAD/CAM zirconia abutment & 3 & 360.55 & 29.66 \\
\hline NobelProcera CAD/CAM ASC Abutment & 3 & 341.45 & 25.97 \\
\hline Aftermarket CAD / CAM zirconia abutment on Ti insert & & & \\
\hline
\end{tabular}

The distance of the mid-buccal fracture surface from the platform of implant fixture was $0 \mathrm{~mm}$ for the All$\mathrm{Zr}$ group, $3.30 \pm 0.32 \mathrm{~mm}$ for the ASC-Zr group, and $4.20 \pm 0.18 \mathrm{~mm}$ for the AM-Zr group. For the midpalatal side, it was $4.91 \pm 1.27 \mathrm{~mm}, 3.78 \pm 0.64 \mathrm{~mm}$ and $5.28 \pm 0.16 \mathrm{~mm}$, respectively (Table 3 ). There was a significant difference in the discrepancy of buccal and palatal height of the fracture in the All-Zr group and the AM-Zr group ( $p<0.05)$, but not in the ASC-Zr group $(p=0.44)$; For the distance of the mid-buccal fracture surface from the platform of implant fixture, there was significant difference $(p<0.05)$ between the 3 groups, as for the mid-palatal site, there was no significant difference between the 3 groups $(p=$ 0.30). The fracture plane of the abutments presented an oblique pattern in the All-Zr group, while in the ASC-Zr group and the AM-Zr group showed a relatively horizontal fracture plane. The modes of failure among the 3 types of abutments are different, but titanium inserts and screws did not show catastrophic damage or fracture (Fig. 5-7). 
Table 3

Modes of failure and mean distance from fracture surface to implant platform of zirconia abutments

\section{Mean (SD) distance from fracture surface to implant platform}

\begin{tabular}{|c|c|c|c|c|c|}
\hline \multirow[t]{2}{*}{ Group } & $\mathrm{n}$ & $\begin{array}{l}\text { Height } \\
\text { of }\end{array}$ & $\begin{array}{l}\text { Mid- } \\
\text { buccal }\end{array}$ & \multirow[t]{2}{*}{$\begin{array}{l}\text { Mid- } \\
\text { palatal }\end{array}$} & \multirow[t]{2}{*}{$\begin{array}{l}\text { Buccal-lingual } \\
\text { discrepancy }\end{array}$} \\
\hline & & $\begin{array}{l}\mathrm{Ti} \\
\text { inserts }\end{array}$ & & & \\
\hline $\begin{array}{l}\text { OEM NobelProcera CAD/CAM zirconia } \\
\text { abutment }\end{array}$ & 3 & & $0 \mathrm{~mm}$ & $\begin{array}{l}4.91 \pm \\
1.27 \mathrm{~mm}\end{array}$ & $4.91 \pm 1.27 \mathrm{~mm}$ \\
\hline $\begin{array}{l}\text { OEM NobelProcera CAD/CAM ASC } \\
\text { Abutment }\end{array}$ & 3 & $1 \mathrm{~mm}$ & $\begin{array}{l}3.30 \pm \\
0.32 \mathrm{~mm}\end{array}$ & $\begin{array}{l}3.78 \pm \\
0.64 \mathrm{~mm}\end{array}$ & $0.48 \pm 0.36 \mathrm{~mm}$ \\
\hline $\begin{array}{l}\text { Aftermarket CAD / CAM zirconia } \\
\text { abutment on } \mathrm{Ti} \text { insert }\end{array}$ & 3 & $2 \mathrm{~mm}$ & $\begin{array}{l}4.20 \pm \\
0.18 \mathrm{~mm}\end{array}$ & $\begin{array}{l}5.28 \pm \\
0.16 \mathrm{~mm}\end{array}$ & $1.08 \pm 0.03 \mathrm{~mm}$ \\
\hline
\end{tabular}

\section{Discussion}

This in vitro study showed that the 3 different types of zirconia abutments had a comparable fracture resistance but different modes of failure under the static load for the platform-switched internal hexagonal implants. Therefore, the null hypothesis could not be rejected. In recent years, zirconia abutments have been increasingly used in clinical applications because of their excellent fracture resistance relative to other ceramic abutments, including abutments made of alumina. Among them, yttrium-stabilized tetragonal zirconia polycrystal (Y-TZP) received the most attention due to its excellent mechanical properties. However, the impact of the load applied on zirconia abutment is still inconclusive. Studies have determined that the type of implant-abutment connection, the physical properties of raw stock, and the manufacturing and experimental methods may significantly affect the abutment strength $^{29}$. Xu et al. ${ }^{30}$ studied the effect of grinding parameters on the strength of Y-TZP. Its strength increased substantially only when $25 \mu \mathrm{m}$ diamond wheel was used in fine machining, while coarse grinding resulted in a decrease in strength. The coarser the diamond wheel they use, the lower the measured strength.

Cyclic loading, which simulates fatigue loading, is the cause of most clinical failures. However, static load tests can simulate situations where the implant complex hits on a hard object and traumatized. In some cases, such as patients with parafunction habits, (e.g., bruxism, clenching, etc.), the incisive force could also be much higher than the physiological range ${ }^{31}$. Cyclic loading and static loading are two independent conditions, and both may affect the settling of the implant-abutment connection after occlusal load ${ }^{32}$. Gehrke et al. ${ }^{21}$ investigated fatigue resistance of one-and two-piece CAD/CAM zirconia abutments and reported that two-piece abutments with an internal-hex connection demonstrated greater resistance to fracture compared to one-piece zirconia abutments and might be clinically beneficial in high-load areas such as posterior tooth replacements. 
The weak point of many all-ceramic abutments is located at the implant-abutment interface. The twopiece abutment design provides metal reinforcement at the implant-abutment connection for greater fracture resistance and meanwhile possesses the ideal aesthetic of all-ceramic abutment ${ }^{22}$. Stimmelmayr et al. ${ }^{33}$ reported that the zirconia implant abutments attached to the titanium core showed higher fracture strength than the one-piece zirconia abutments and indicated that they may be more suitable for clinical use. The authors also suggested that titanium implants exhibited higher interface wear under cyclic loading when attached to one-piece zirconia abutments than attached to titanium abutments ${ }^{34}$. In this regard, two-piece abutment with titanium-titanium connections may be beneficial for clinical applications.

It has been reported that implant abutments with internal hexagonal connections are more stable than external hexagonal designs because of their wider stress distribution along the interface ${ }^{35}$. However, Sailer et al. ${ }^{24}$ concluded that under oblique loading, internally connected one-piece zirconia abutments are less resistant to fracture than externally connected one-piece zirconia abutments. The mean fracture load of externally connected (NobelBiocare) zirconia abutments is $480.9 \mathrm{~N}( \pm 182.8)$, whereas that of internally connected (Straumann, Basel, Switzerland) zirconia abutments is $292.0 \mathrm{~N}( \pm 218.4)$, which is similar to the maximum load measured in present study. The fracture resistance of the 3 types of zirconia abutments is within the physiological shear range of the anterior zone (approximately 90 to $370 \mathrm{~N}$ ). Whether the mechanical strength is sufficient for long-term use in the anterior region remains to be confirmed by more clinical studies.

Along with the introduction of CAD/CAM and aftermarket prosthetic components into the clinical use, non-original abutments receive more attention. Although aftermarket zirconia abutments showed similar fracture resistance with OEM zirconia abutments in current study, Gigandet et al. ${ }^{22}$ reported aftermarket abutments that changed the original design and materials showed higher rotational misfit. This mismatch may result in increased wear and micromotion between the titanium and zirconia interfaces, ultimately lead to surface flaws and zirconia $\mathrm{cracks}^{36}$. In comparing the torque loss of four types of abutments, Park et al. ${ }^{37}$ reported that the torque loss of original abutments was lower than those of copy abutments. Similar result was obtained by Alonso-Pérez et al. ${ }^{38}$ and concluded that internal precision at the implant-abutment connections is a crucial determinant to the mechanical properties of abutments, possibly explaining the superiority of original abutments over its non-original counterparts. However, few clinical studies have evaluated the effects of non-original abutments on implants. Therefore, more clinical studies should be conducted to test the incidence of failure and complications of implant complexes with the original and non-original connections.

In All-Zr group, the zirconia abutments showed an oblique fracture pattern. The fracture surface was higher at palatal side of the abutments and significantly lower at buccal side, showing an oblique fracture line starting from the buccal aspect at the region of the implant platform, which is similar to the results of the study reported by Nothdruft et al. ${ }^{27}$ In those zirconia abutments with a titanium insert, the fracture surface showed a relatively horizontal pattern, which demonstrated titanium inserts raises the buccal fracture surface away from the implant platform, the level of fracture surface at buccal side of zirconia 
abutments increased with the height of the titanium inserts, which may have the effect of protecting the implant-abutment connection. Kim et al. ${ }^{39}$ compared the modes of failure among 3 different zirconia abutments after static load. The abutment consisted entirely of zirconia showed fractures arisen from the connection area. The zirconia abutment with friction-fitted titanium insert showed fractures generated from the contact area between zirconia and the screw head. The zirconia abutment with bonded titanium insert showed the separation between the two parts. The results demonstrated that the mode of failure among three types of zirconia abutments was different. However, the present study demonstrated the zirconia abutment with titanium inserts had a similar mode of failure with different height of fracture surfaces, which depended on the height of titanium inserts.

Clinically, the deeper the abutment structure damaged may make the clinicians more difficult to manage, increasing the complexity of complication. The removal of fractured components may cause irreversible damage to the implant platform and internal structure, and if catastrophically damaged, the implant fixture may need to be surgically removed or replaced. Therefore, the titanium inserts might keep fracture surface away from the implant platform and is beneficial to the clinicians to replace implant prostheses. In this study, there was no catastrophic damage or fracture of the abutment screws or implants founded, which is consistent with the results of studies conducted by Mitsias et al. ${ }^{17}$. This mode of failure is quite different from titanium abutments. Yilmaz et al. ${ }^{40}$ investigated five different titanium abutments for load to failure, with four of which showing fracture of retentive screw. Only one abutment did not show any components to fracture, but eventually, bending of the screw beyond the plastic range did occur.

The limitations of this study require careful interpretation to correctly explain the clinical implications. The first is the use of static load rather than cyclic load in this study. However, this static load test can be regarded as a preliminary study, future fatigue load projects can be designed based upon the mean failure load in this study. Secondly, this study uses only internal hexagonal connections and standard diameter implants with one implant system, the results may not be applicable to other implant systems. Therefore, additional clinical studies are needed to determine the clinical performance of various zirconia abutments and to provide guidelines for clinical use.

\section{Conclusions}

Within the limitations of this in vitro study, the following conclusions were drawn:

1. There was no significant difference in fracture resistance between the 3 types of zirconia abutments with different implant-abutment composition.

2. The presence or absence of a titanium insert affects the modes of failure in zirconia abutments. When there is a titanium reinforcement, the abutment presents a relatively horizontal fracture surface, and if not, it exhibits an oblique fracture. In addition, the titanium insert will keep the buccal fracture surface of the zirconia abutment away from the implant platform, thereby protecting the implant-abutment connection. 


\section{Declarations}

\section{Acknowledgements}

This research was supported by the following government and academic organizations: Chang Gung Medical Foundation and Cheng Shiu University (CMRPG8G0011). The authors would like to thank all colleagues who contributed to this study and statistical assistance of Kaohsiung Chang Gung Memorial Hospital Biostatistics Center.

\section{Authors' contributions}

Y.W and J.C contributed to the data curation and conceptualization, A.Y.W. contributed to the project administration and supervision, M.T and H.C contributed to the methodology, Y.C contributed to the investigation and writing of this paper. All authors have read and agreed to the published version of the manuscript.

\section{Competing interests}

The authors declare no competing interests.

\section{References}

1. Adell R, Lekholm U, Rockler B \& Brånemark PI. A 15-year study of osseointegrated implants in the treatment of the edentulous jaw. Int J Oral Surg. 10, 387-416 (1981).

2. Buser $D$ et al. Long-term evaluation of non-submerged ITI implants. Part 1: 8-year life table analysis of a prospective multi-center study with 2359 implants. Clin Oral Implants Res. 8, 161-172 (1997).

3. Jung RE, Holderegger C, Sailer I, Khraisat A, Suter A \& Hämmerle CH. The effect of all-ceramic and porcelain-fused-to-metal restorations on marginal peri-implant soft tissue color: a randomized controlled clinical trial. Int J Periodontics Restorative Dent. 28, 357-365 (2008).

4. Prestipino V \& Ingber A. All-ceramic implant abutments: esthetic indications. J Esthet Dent. 8, 255262 (1996).

5. Bressan E, Paniz G, Lops D, Corazza B, Romeo E \& Favero G. Influence of abutment material on the gingival color of implant supported all-ceramic restorations: a prospective multicenter study. Clin Oral Implants Res. 22, 631-637 (2011).

6. Prestipino V \& Ingber A. Esthetic high strength implant abutments. Part I. J Esthet Dent. 5, 29-36 (1993).

7. Prestipino V \& Ingber A. Esthetic high strength implant abutments. Part II. J Esthet Dent. 5, 63-68 (1993).

8. Yildirim M, Fisher H, Marx R \& Edelhoff D. In vivo fracture resistance of implant-supported all-ceramic restorations. J Prosthet Dent. 4, 325-331 (2003). 
9. Butz F, Heydecke G, Okutan M \& Strub JR. Survival rate, fracture strength and failure mode of ceramic implant abutments after chewing simulation. J Oral Rehabil. 32, 838-843 (2005).

10. Wohlwend A, Studer S \& Scharer P. Das zirkonoxidabutment ein neues vollkeramisches konzept zur ästhetischen verbesserung der suprastruktur in der implantologie. Quint Zahnt. 22, 364-381 (1996).

11. Gibbs CH, Mahan PE, Mauderli A, Lundeen HC \& Walsh EK. Limits of human bite strength. J Prosthet Dent. 56, 226-229 (1986).

12. Baldissara P, Llukacej A, Ciocca L, Valandro FL \& Scotti R. Translucency of zirconia copings made with different CAD/CAM systems. J Prosthet Dent. 104, 6-12 (2010).

13. Paphangkorakit $\mathrm{J} \&$ Osborn JW. The effect of pressure on a maximum incisal bite force in man. Arch Oral Biol. 42, 11-17 (1997).

14. Helkimo E, Carlsson GE \& Helkimo M. Bite force and state of dentition. Acta Odontol Scand. 35, 297303 (1977).

15. Haraldson T, Carlsson GE \& Ingervall B. Functional state, bite force and postural muscle activity in patients with osseointegrated oral implant bridges. Acta Odontol Scand. 37, 195-206 (1979).

16. Waltimo A \& Könönen M. A novel bite force recorder and maximal isometric bite force values for healthy young adults. Scand J Dent Res. 101,171-175 (1993).

17. Mitsias ME, Silva NR, Pines M, Stappert C \& Thompson VP. Reliability and fatigue damage modes of zirconia and titanium abutments. Int J Prosthodont. 23, 56-59 (2010).

18. Kim S, Kim HI, Brewer JD \& Monaco EA Jr. Comparison of fracture resistance of pressable metal ceramic custom implant abutments with CAD/CAM commercially fabricated zirconia implant abutments. J Prosthet Dent. 101, 226-230 (2009).

19. Luthardt RG et al. Reliability and properties of ground Y-TZP-zirconia ceramics. J Dent Res. 81, 487491 (2002).

20. Leutert CR, Stawarczyk B, Truninger TC, Hämmerle CH \& Sailer I. Bending moments and types of failure of zirconia and titanium abutments with internal implant-abutment connections: A laboratory study. Int J Oral Maxillofac Implants. 27, 505-512 (2012).

21. Gehrke P, Johannson D, Fischer C, Stawarczyk B \& Beuer F. In vitro fatigue and fracture resistance of one- and two-piece CAD/CAM zirconia implant abutments. Int J Oral Maxillofac Implants. 30, 546554 (2015).

22. Gigandet M, Bigolin G, Faoro F, Bürgin W \& Brägger U. Implants with original and non-original abutment connections. Clin Implant Dent Relat Res. 16, 303-311 (2014).

23. Jarman JM, Hamalian T \& Randi AP. Comparing the fracture resistance of alternatively engineered zirconia abutments with original equipment manufactured abutments with different implant connection designs. Int J Oral Maxillofac Implants. 32, 992-1000 (2017).

24. Sailer I, Sailer T, Stawarczyk B, Jung RE \& Hämmerle CH. In vitro study of the influence of the type of connection on the fracture load of zirconia abutments with internal and external implant-abutment connections. Int J Oral Maxillofac Implants. 24, 850-858 (2009). 
25. Yildirim M, Fischer H, Marx R \& Edelhoff D. In vivo fracture resistance of implant-supported allceramic restorations. J Prosthet Dent. 90, 325-331 (2003).

26. Adatia ND, Bayne SC, Cooper LF \& Thompson JY. Fracture resistance of yttria-stabilized zirconia dental implant abutments. J Prosthodont. 18, 17-22 (2009).

27. Nothdurft FP, Doppler KE, Erdelt KJ, Knauber AW \& Pospiech PR. Fracture behavior of straight or angulated zirconia implant abutments supporting anterior single crowns. Clin Oral Investig. 15, 157$163(2011)$.

28. Gehrke $\mathrm{P}$ et al. Zirconium implant abutments: fracture strength and influence of cyclic loading on retaining-screw loosening. Quintessence Int. 37, 19-26 (2006).

29. Park Jl et al. Comparison of fracture resistance and fit accuracy of customized zirconia abutments with prefabricated zirconia abutments in internal hexagonal implants. Clin Implant Dent Relat Res.15(5), 769-778 (2013).

30. Xu HKK, Jahanmir S \& Ives LK. Effect of grinding on strength of tetragonal zirconia and zirconiatoughened alumina. Mach Sci Tech. 1, 49-66 (1997).

31. Stuebinger, S.; Hodel, Y. \& Filippi, A. Trauma to anterior implants. Dent. Traumatol. 2, 169-171 (2004).

32. Kim K-S \& Lim Y-J. Axial Displacements and Removal Torque Changes of Five Different ImplantAbutment Connections under Static Vertical Loading. Materials. 13(3), 699 (2020).

33. Stimmelmayr M, Sagerer S, Erdelt K \& Beuer F. In vitro fatigue and fracture strength testing of onepiece zirconia implant abutments and zirconia implant abutments connected to titanium cores. Int $\mathrm{J}$ Oral Maxillofac Implants. 28, 488-493 (2013).

34. Stimmelmayr $\mathrm{M}$ et al. Wear at the titanium-titanium and the titanium-zirconia implant-abutment interface: A comparative in vitro study. Dent Mater. 28,1215-1220 (2012).

35. Maeda, Y., Satoh, T. \& Sogo, M. In vitro differences of stress concentrations for internal and external hex implant-abutment connections: a short communication. J Oral Rehabil. 33, 75-78 (2006).

36. Klotz MW, Taylor TD \& Goldberg AJ. Wear at the titanium-zirconia implant-abutment interface: A pilot study. Int J Oral Maxillofac Implants. 26, 970-975 (2011).

37. Park JM et al. An in vitro evaluation of the loosening of different interchangeable abutments in internal-connection type implants. Int J Oral Maxillofac Implants. 32, 350-355 (2017).

38. Alonso-Pérez R, Bartolomé JF, Ferreiroa A, Salido MP \& Pradíes G. Original vs. nonoriginal abutments for screw-retained single implant crowns: an in vitro evaluation of internal fit, mechanical behaviour and screw loosening. Clin Oral Implants Res. 29, 1230-1238(2018).

39. Kim JS et al. In vitro assessment of three types of zirconia implant abutments under static load. J Prosthet Dent. 109, 255-263 (2013).

40. Yilmaz B, Salaita LG, Seidt JD, Clelland NL \& McGlumphy EA. Load to failure of different titanium abutments for an internal hexagon implant. J Prosthet Dent. 114, 513-516 (2015). 


\section{Figures}

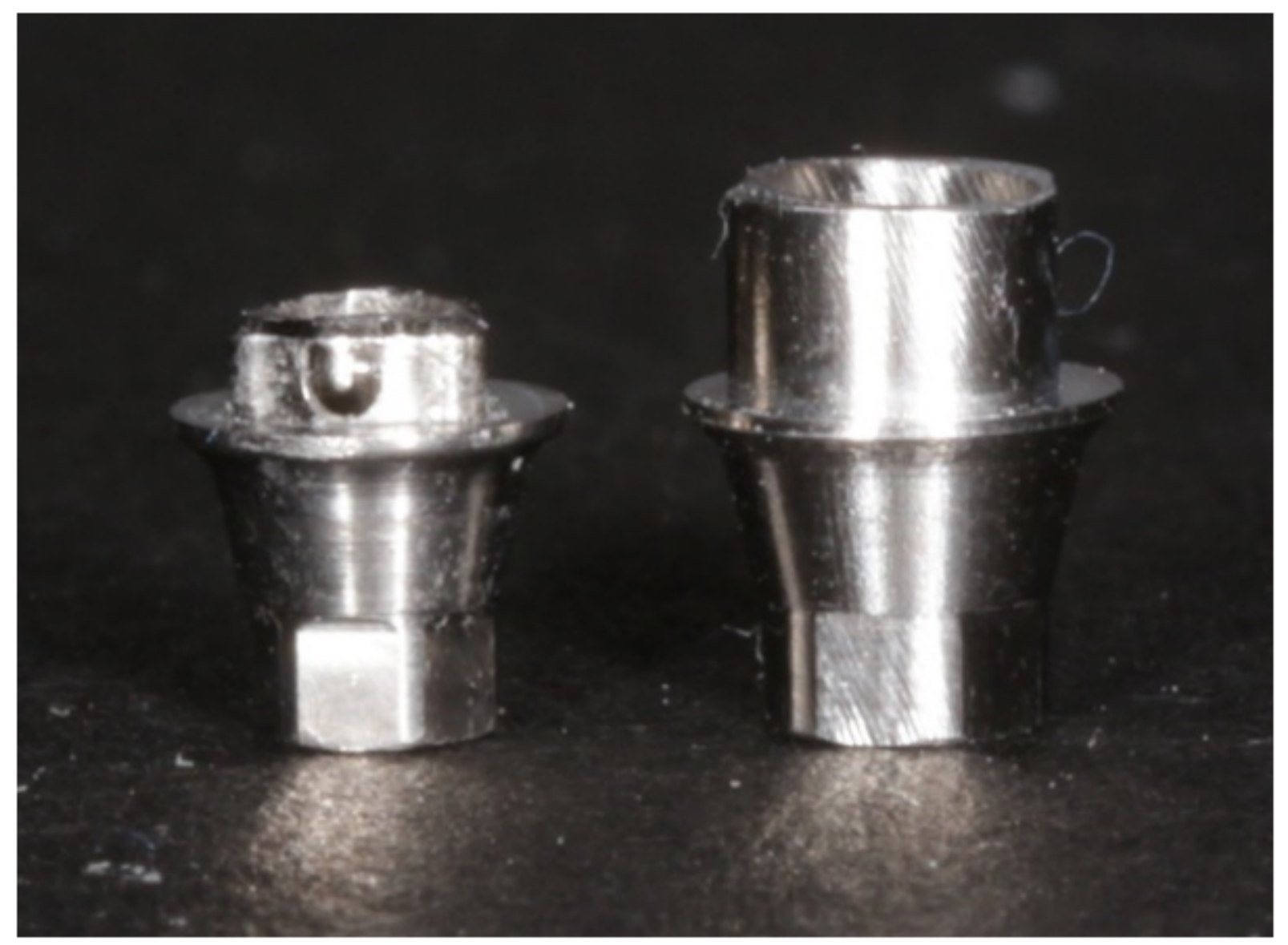

\section{Figure 1}

Titanium insert of NobelProcera ASC abutment (Left) and aftermarket abutments (Right). 


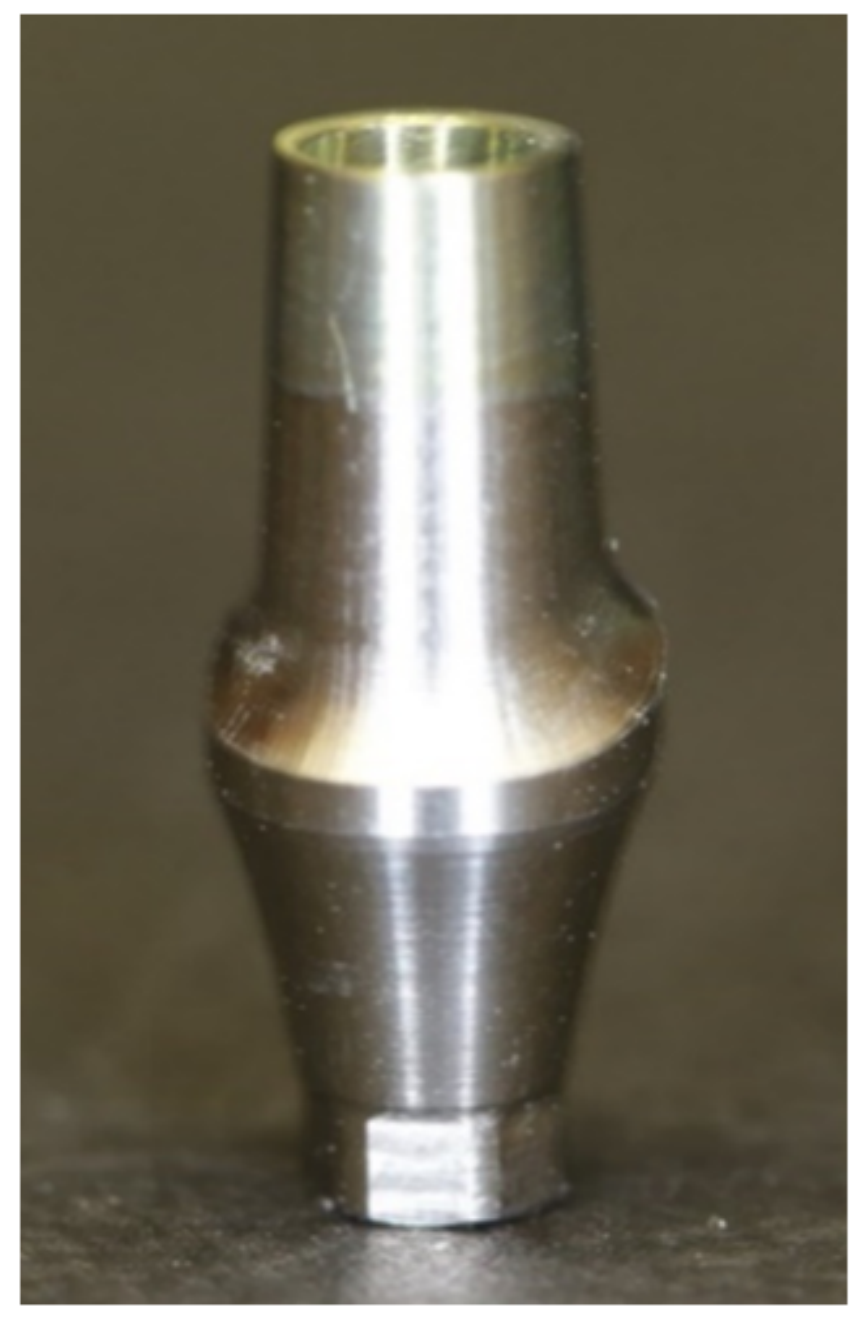

Figure 2

Titanium prototype abutment (NobelReplace Abutment Conical Connection RP 3 mm). 


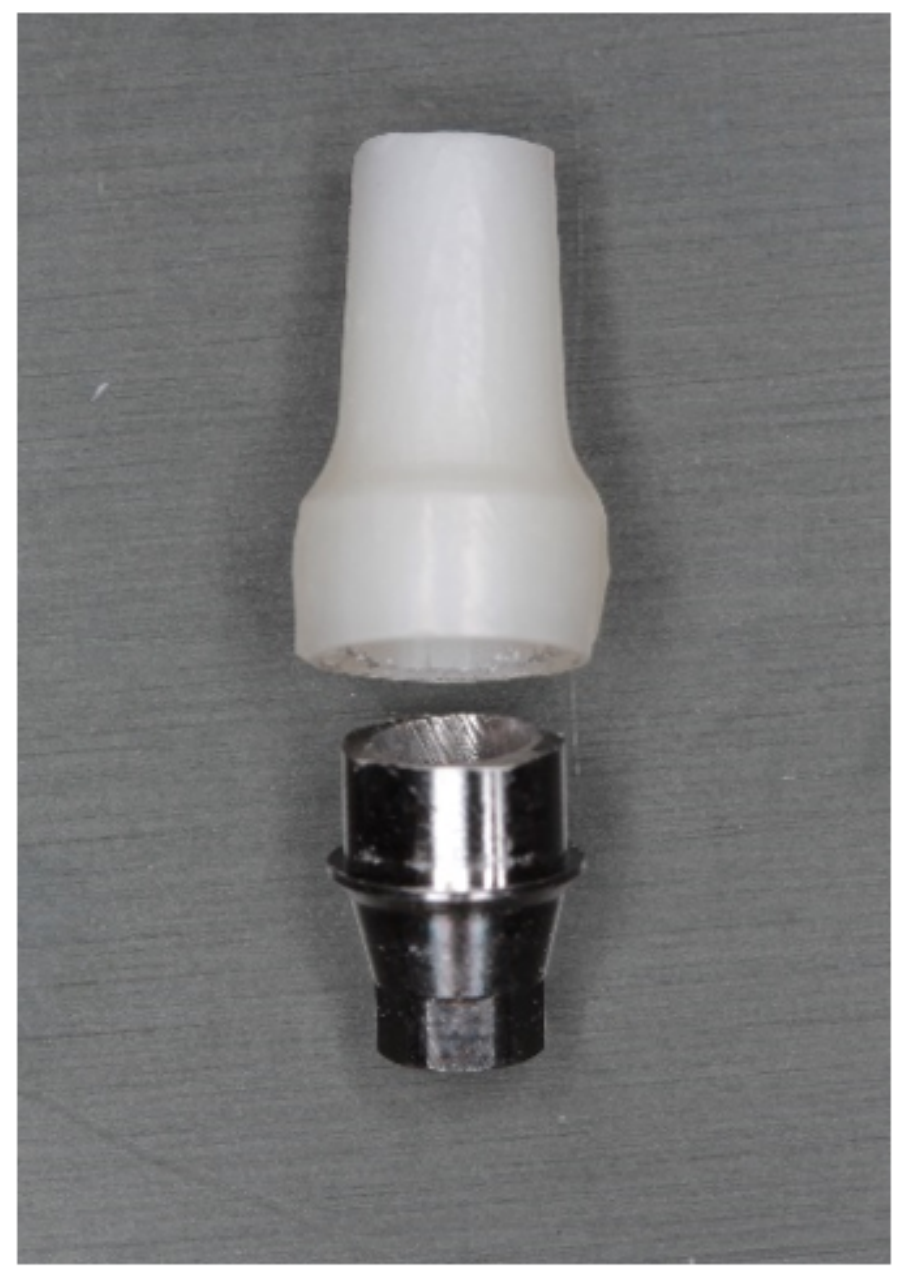

Figure 3

The titanium insert and corresponding zirconia component of AM-Zr abutment. 


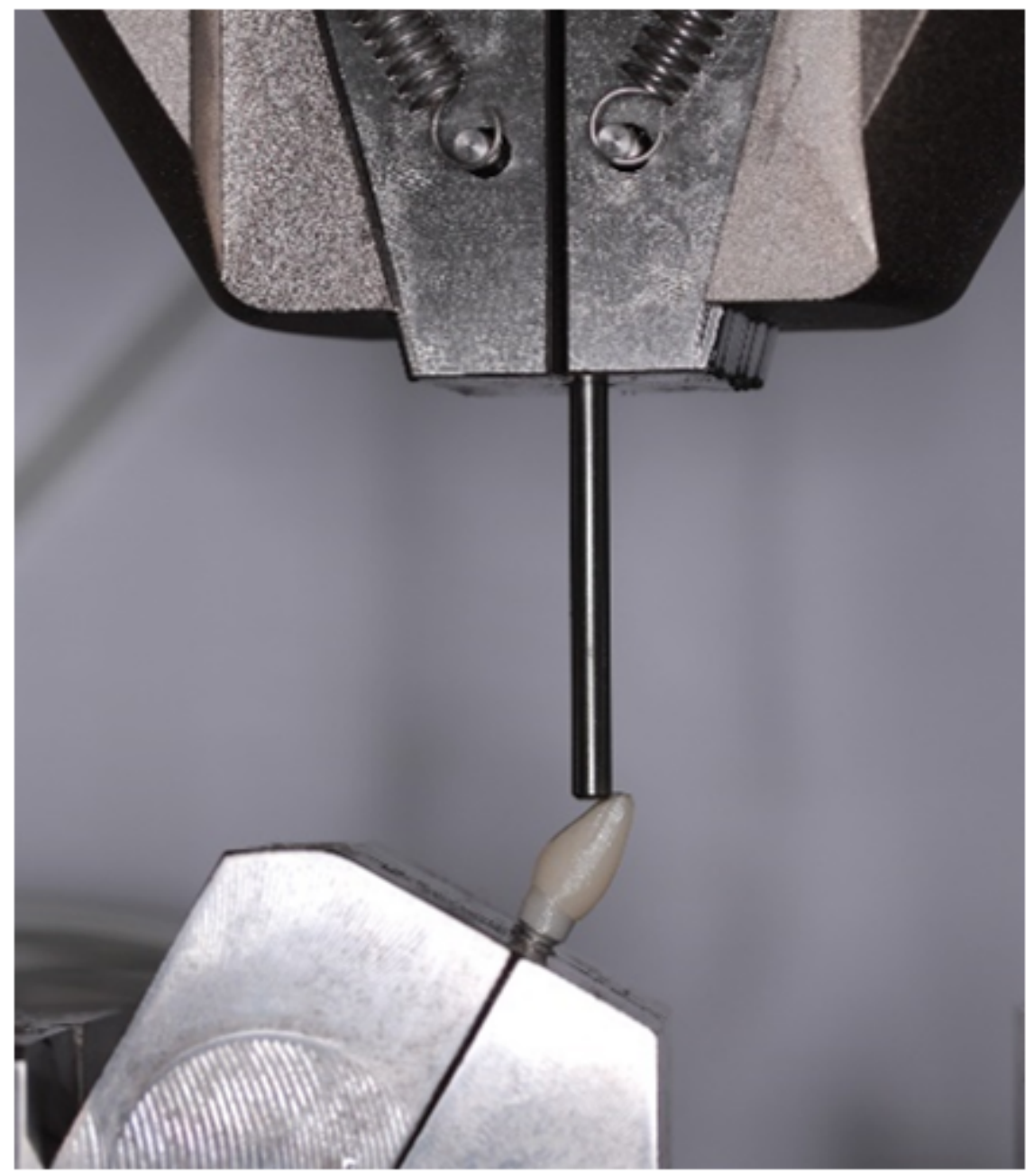

\section{Figure 4}

Thirty-degree loading of the assembled specimen with a universal testing machine.
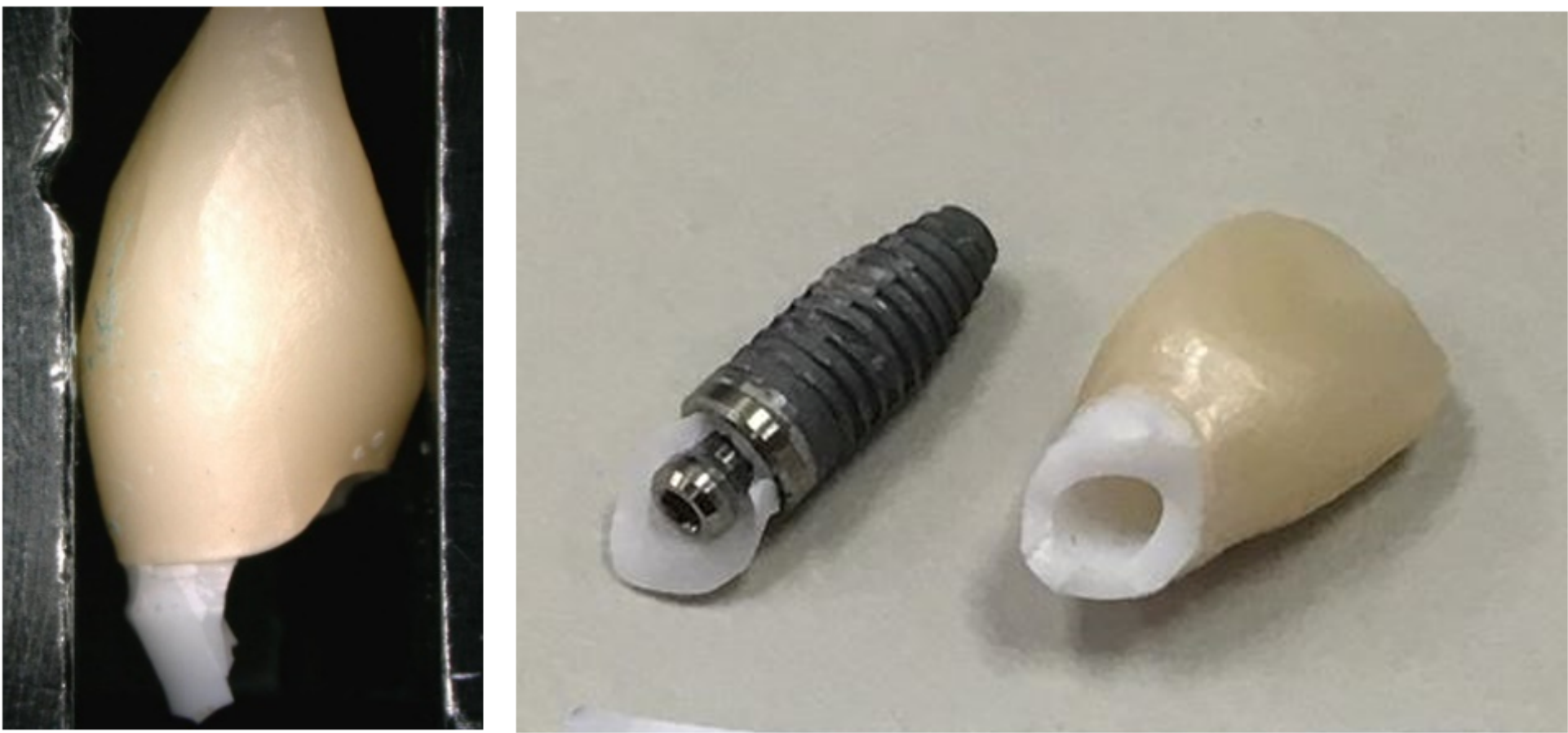


\section{Figure 5}

Typical fracture mode in All-Zr group (oblique fracture line starting from the buccal aspect in the region of the internal hexagon)
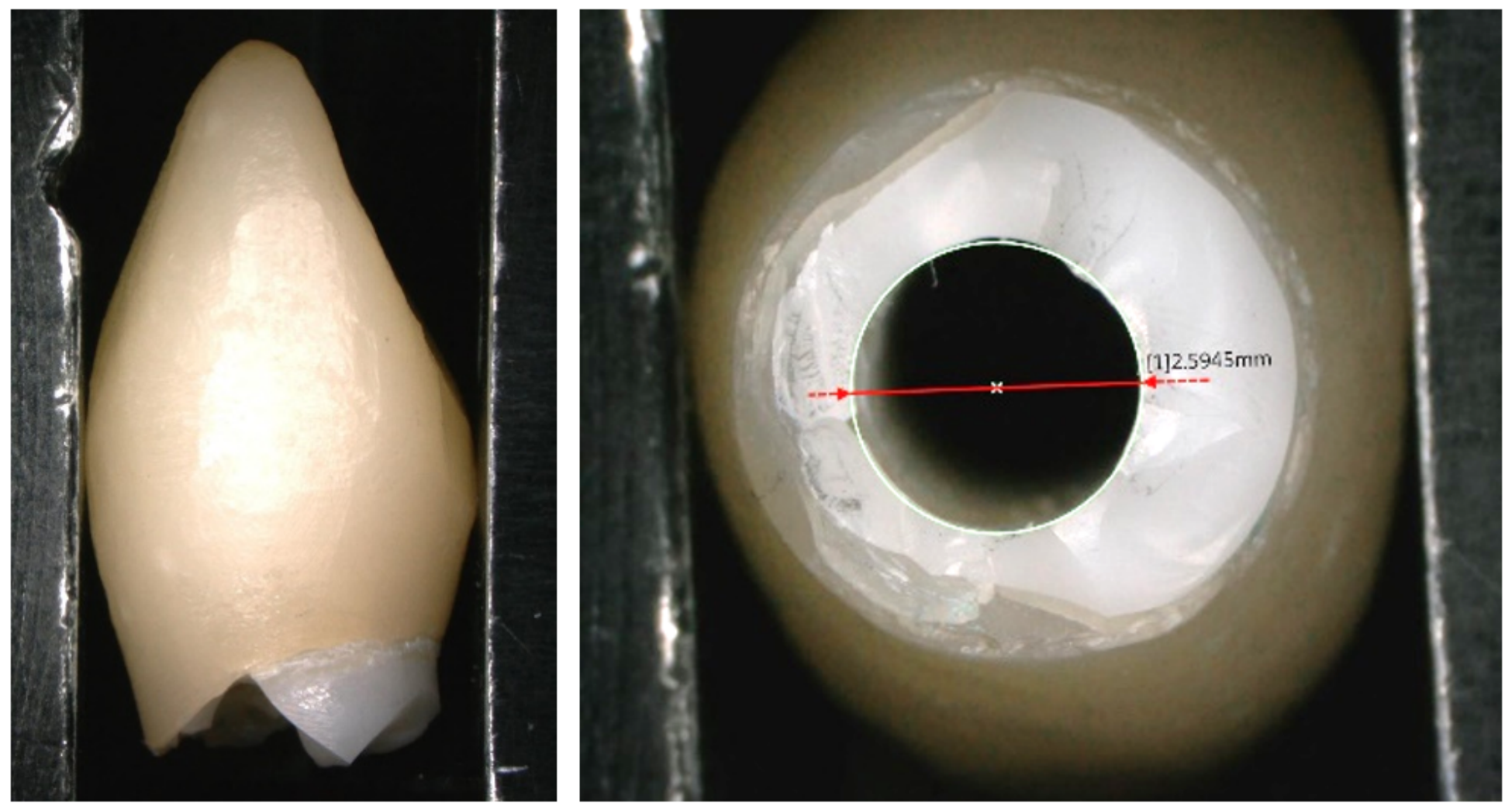

\section{Figure 6}

Fracture mode in ASC-Zr group (a relatively horizontal pattern with buccal fracture surface away from the implant platform). 

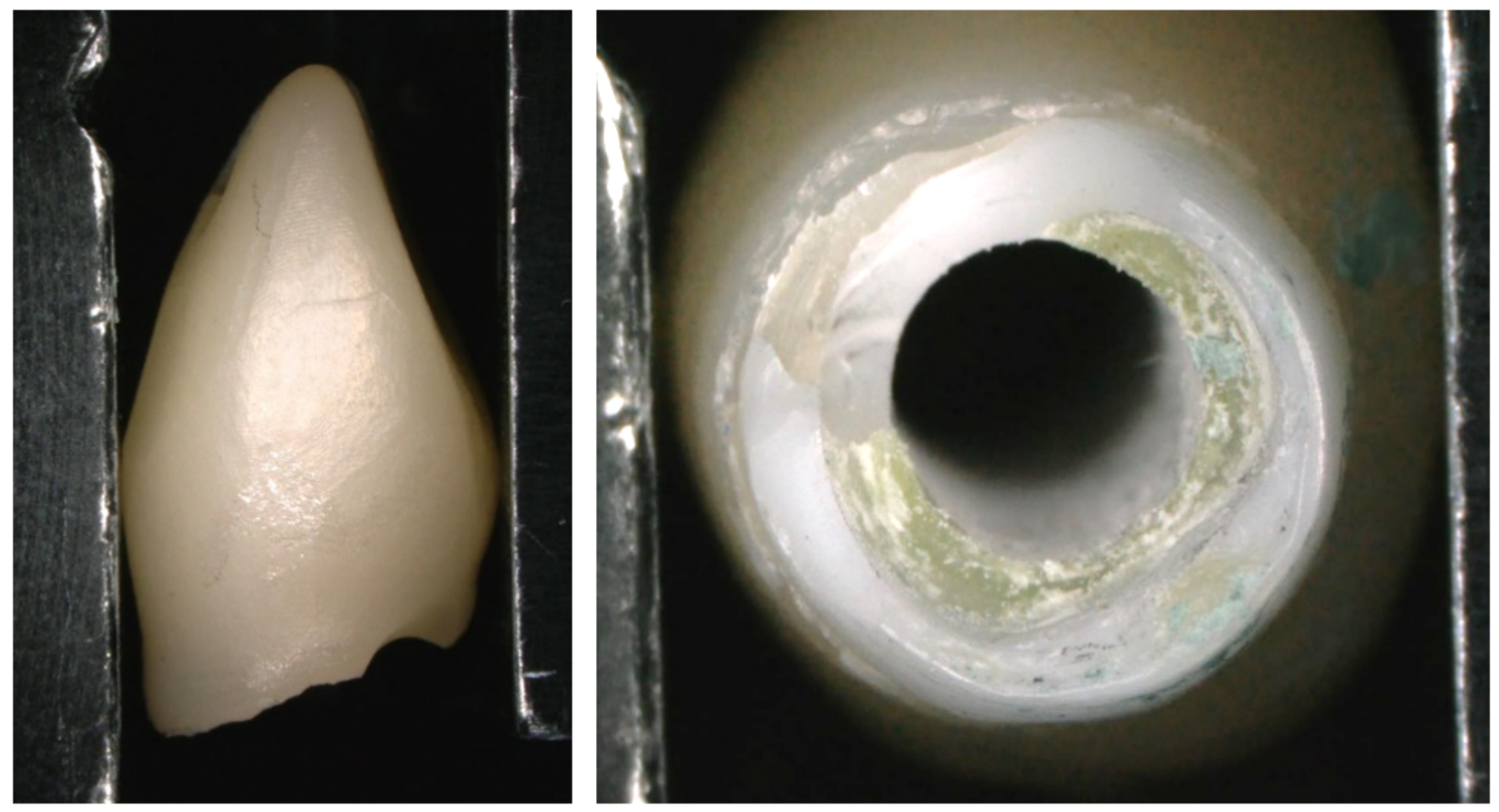

\section{Figure 7}

Fracture mode in AM-Zr group (horizontal fracture pattern similar to ASC-Zr group, but the fracture surface is even higher) 